University of Nebraska - Lincoln

DigitalCommons@University of Nebraska - Lincoln

1993

\title{
Eddy Correlation Measurement of CO2 Flux Using a Closed-Path Sensor: Theory and Field Tests Against an Open-Path Sensor
}

\author{
A. E. Suyker \\ University of Nebraska - Lincoln \\ S. B. Verma \\ University of Nebraska - Lincoln
}

Follow this and additional works at: https://digitalcommons.unl.edu/natrespapers

Part of the Natural Resources and Conservation Commons, Natural Resources Management and Policy Commons, and the Other Environmental Sciences Commons

Suyker, A. E. and Verma, S. B., "Eddy Correlation Measurement of CO2 Flux Using a Closed-Path Sensor: Theory and Field Tests Against an Open-Path Sensor" (1993). Papers in Natural Resources. 1208. https://digitalcommons.unl.edu/natrespapers/1208

This Article is brought to you for free and open access by the Natural Resources, School of at DigitalCommons@University of Nebraska - Lincoln. It has been accepted for inclusion in Papers in Natural Resources by an authorized administrator of DigitalCommons@University of Nebraska - Lincoln. 


\title{
EDDY CORRELATION MEASUREMENT OF $\mathrm{CO}_{2}$ FLUX USING A CLOSED-PATH SENSOR: THEORY AND FIELD TESTS AGAINST AN OPEN-PATH SENSOR ${ }^{1}$
}

\author{
ANDREW E, SUYKER and SHASHI B. VERMA \\ Department of Agricultural Meteorology, University of Nebraska-Lincoln, Lincoln, \\ NE 68583-0728, U.S.A.
}

(Received in final form 4 September, 1992)

\begin{abstract}
We have examined the potential of using a closed-path sensor to accurately measure eddy fluxes of $\mathrm{CO}_{2}$. Five inlet tubeflow configurations were employed in the experimental setup. The fluxes of $\mathrm{CO}_{2}$ were compared against those measured with an open-path sensor. Sampling air through an intake tube causes a loss of flux, due to the attenuation of $\mathrm{CO}_{2}$ density fluctuations. Adjustments need to be made to correct for this loss and to account for density effects due to the simultaneous transfer of heat and water vapor. Theory quantifying these effects is discussed.

The "raw" $\mathrm{CO}_{2}$ flux measured with the closed-path sensor was smaller than that measured with the open-path sensor by about $15 \%$ (on average) for the turbulent tubeflow configurations with a short $(\approx 3 \mathrm{~m})$ intake tube, by $31 \%$ for turbulent tubeflow with a longer $(\approx 6 \mathrm{~m})$ intake tube and by $24 \%$ for laminar tubeflow. The difference was, in part, caused by tube attenuation of the $\mathrm{CO}_{2}$ density fluctuations and inadequate sensor time response. The elimination of the flux adjustment for the simultaneous transfer of sensible heat (i.e., the attenuation of ambient temperature fluctuations in the intake tube) generally accounted for the rest of this difference.

The raw flux measured with the closed-path sensor was corrected for frequency response and density effects. Except in the case of laminar tubeflow, the corrected closed-path flux agreed consistently with the corrected open-path flux within a few percent $(<5 \%)$. These results suggest that closed-path sensors, with appropriate corrections, can be used to measure $\mathrm{CO}_{2}$ flux accurately. Recommendations are included on selecting an "optimum" flow configuration to minimize the effect of sampling air through a tube.
\end{abstract}

\section{Introduction}

Eddy correlation measurements of some trace gases have been made by drawing the air through an intake tube into a sensing chamber or cell (e.g., Fan et al., 1990; Zeller et al., 1989; McMillen, 1988; Hicks et al., 1986; Wesley et al., 1978). Measuring gas concentration fluctuations using a closed-path sensor may have some advantages compared to the open-path sensor. Spectral energy loss due to the separation between the velocity sensor and the intake tube may be minimized by mounting the intake tube very close to the vertical velocity sensor. Flow distortion will also be minimal. Adjustments to trace gas fluxes due to the simultaneous transfer of sensible heat and water vapor (e.g., Webb, Pearman, and Leuning, 1980 - hereafter WPL) may be reduced by sampling air through an intake tube. For example, the air temperature fluctuations may be completely

1 Published as Paper No. 9938, Journal Series, Nebraska Agricultural Research Division.

${ }^{2}$ Graduate Student and Professor, respectively. 
attenuated in a metal intake tube thus removing the need to adjust the trace gas flux for simultaneous heat transfer (e.g., Leuning and Moncrieff, 1990). It may, however, be necessary to correct trace gas fluxes measured with closed-path sensors for spectral energy loss due to the attenuation of trace gas density fluctuations in the intake tube and inadequate sensor time response.

The objectives of this paper are to: (a) discuss the theory concerning the effect of sampling air through an intake tube on the measurement of $\mathrm{CO}_{2}$ flux and (b) evaluate the potential of a closed-path $\mathrm{CO}_{2}$ sensor to make accurate eddy correlation flux measurements. In evaluating the closed-path sensor, two models were applied to account for tube attenuation of the ambient $\mathrm{CO}_{2}$ fluctuations: the first is a recently developed model by Massman (1991) for turbulent tubeflow and the second is a model by Philip (1963c) for laminar tubeflow.

\section{Theory of Closed-path Measurements}

Measurements of $\mathrm{CO}_{2}$ fluxes using open- or closed-path sensors require corrections for (a) imperfect frequency response and (b) the effect of the simultaneous transfer of sensible heat and water vapor (WPL adjustment). The spectral energy loss due to imperfect frequency response is estimated from turbulent structure theory (e.g., Kaimal et al., 1972) and applied to the "raw" flux (e.g., see Moore, 1986). The WPL adjustment is applied subsequently to the frequency response corrections. Corrections applied to fluxes measured with open-path sensors have been recently discussed in Businger (1986), Baldocchi et al. (1988), Leuning and Moncrieff (1990), Verma (1990) and others. Flux measurements with closed-path sensors may require additional frequency response corrections and a WPL adjustment, as discussed below.

\subsection{Tube attenuation}

The intake tube acts as a "low-pass filter" which attenuates the high frequency ambient $\mathrm{CO}_{2}$ density fluctuations (e.g., Leuning and Moncrieff, 1990). Attenuation of gas concentration fluctuations for tubeflows has been studied by Taylor (1953, 1954), Philip (1963a, b, c), Barton (1983), Lenschow and Raupach (1991), Massman (1991) and others. In these investigations, transfer functions, defined as the ratio of the Fourier transforms of the input signal to the output signal, have been developed to describe tube attenuation. The transfer function, $T_{t}(n)$ as a function of natural frequency, $n(\mathrm{~Hz})$, can be given by (Massman, 1991):

$$
T_{t}(n)=\exp \left[-4 \pi^{2} n^{2} \Lambda L a u_{t}^{-2}\right],
$$

where $\Lambda$ is a tube attenuation coefficient for the $\mathrm{CO}_{2}$ gas, $L$ is the tube length, $a$ is the tube radius, and $u_{t}$ is the mean flow velocity in the tube. For turbulent tubeflow ( $\operatorname{Re}>2300$ ), Massman (1991) gives the attenuation coefficient as:

$$
\Lambda=0.5 \nu \operatorname{Re}\left|\lambda_{i}\right| \Omega^{-1} D_{\max }^{-1},
$$


where $\nu$ is kinematic viscosity of air, Re is the Reynolds number $\left(2 u_{t} a \nu^{-1}\right), \lambda_{i}$ is the imaginary part of a complex eigenvalue, $\Omega\left(2 \pi n a^{2} D_{\max }^{-1}\right)$ is a non-dimensional oscillation frequency of the gas concentration at the tube inlet, and $D_{\max }$ is the maximum diffusivity of the radial turbulent diffusivity profile in the tube. For turbulent tubeflow, the transfer function is valid if $L / a>0.25 \nu \operatorname{Re} D_{m}^{-1}$, where $D_{m}$ is the mean of the turbulent diffusivity profile in the tube. Massman (1991) provides values of $\Lambda$ and $0.25 \nu \operatorname{Re} D_{m}^{-1}$ for various Reynolds numbers as well as for gases of different molecular diffusivities (the molecular diffusivity determines the turbulent diffusivity profile which alters the attenuation coefficient). For laminar tubeflow $(\operatorname{Re}<2100)$ the tube attenuation coefficient can be obtained from Philip (1963c):

$$
\Lambda=0.0104 \nu \operatorname{Re} D^{-1},
$$

where $D$ is the molecular diffusivity of $\mathrm{CO}_{2}$ gas. The transfer function for laminar flow is valid for $\Omega<10$, where $\Omega=2 \pi n a^{2} D^{-1}$, and $L / a \gg 0.05 \nu \operatorname{Re} D^{-1}$.

For both turbulent and laminar tubeflows, the attenuation coefficient is independent of oscillation frequency (the term $\left|\lambda_{i}\right| \Omega^{-1}$ in Equation (2) is independent of oscillation frequency - Massman, 1991). Also, the transfer function, $T_{t}(n)$, is an exponential function of frequency squared and therefore, this "low-pass filter" has relatively rapid attenuation past the tube attenuation cutoff frequency, $n_{c}$. At $n_{c}$ by definition, the transfer function has the value of $1 / \sqrt{2}$. Substituting $T_{t}\left(n_{c}\right)=1 / \sqrt{2}$ in Equation (1) and simplifying gives:

$$
n_{c}=\left[8.779 \times 10^{-3} u_{t}^{2}(\Lambda L a)^{-1}\right]^{1 / 2} .
$$

The tube attenuation cutoff frequency is useful in comparing the relative effect of tube attenuation for different tubeflows under similar atmospheric conditions. Larger values of $n_{c}$ would correspond to less tube attenuation and therefore, smaller losses in flux.

\subsection{Webb, Pearman, and Leuning (WPL) adjustment}

In case of an open-path sensor, the total flux of carbon dioxide, $F_{c}$ is given (e.g., see Webb et al., 1980) as:

$$
F_{c}=\overline{w^{\prime} \rho_{c}^{\prime}}+\mu\left(\overline{\rho_{c}} / \overline{\rho_{a}}\right) \overline{w^{\prime} \rho_{v}^{\prime}}+(1+\mu \sigma)\left(\bar{\rho}_{c} / \bar{T}\right) \overline{w^{\prime} T^{\prime}},
$$

where $w$ is the vertical velocity, $\rho_{c}, \rho_{v}$, and $\rho_{a}$ are the densities of $\mathrm{CO}_{2}$, water vapor, and dry air, $\mu$ is the ratio of molecular weights of water to dry air, $\sigma=$ $\overline{\rho_{\nu}} / \bar{\rho}_{a}$ is the mean density ratio of water vapor to dry air, and $T$ is the temperature. The prime denotes fluctuations from the mean and the overbar denotes time averages. Note in Equations (5)-(9) that the covariances (or fluxes) have been corrected for the appropriate frequency response (e.g., tube attenuation and time response).

Using a closed-path sensor allows for a partial or complete elimination of the WPL adjustment (e.g., Leuning and Moncrieff, 1990; Fan et al., 1990). Sampling 
air through a metal intake tube can completely attenuate temperature fluctuations (see Leuning and Moncrieff, 1990; Incropera and DeWitt, 1981). If the $\mathrm{CO}_{2}$ density and humidity $\left(\rho_{c 1}\right.$ and $\left.\rho_{\nu 1}\right)$ are simultaneously measured in the cell at constant temperature, $\bar{T}_{\mathrm{I}}$, and pressure, $\bar{P}_{\mathrm{I}}$ (or if fluctuations in $T_{\mathrm{I}}$ and $P_{\mathrm{I}}$ are not correlated with $w^{\prime}$ ), the total $\mathrm{CO}_{2}$ flux $F_{c}$ is given as:

$$
F_{c}=\left(\bar{P} / \bar{P}_{\mathrm{I}}\right)\left(\bar{T}_{\mathrm{I}} / \bar{T}\right)\left[\overline{w^{\prime} \rho_{c \mathrm{I}}^{\prime}}+\mu\left(\bar{\rho}_{c} / \overline{\rho_{a}}\right) \overline{w^{\prime} \rho_{v I}^{\prime}}\right] .
$$

(Equation (6) can be obtained by substituting eddy covariances for mixing-length relationships in Equation (36) of Webb et al. (1980), noting that $\bar{\rho}_{c} / \bar{\rho}_{a}=\bar{\rho}_{c \mathrm{l}} / \bar{\rho}_{a \mathrm{I}}$.) The terms $\bar{T}$ and $\bar{P}$ are mean ambient temperature and pressure. Note that an adjustment (WPL) for the simultaneous transfer of water vapor is included in Equation (6) but there is no adjustment for the simultaneous transfer of sensible heat. The sensible heat is absorbed into the tube wall as the temperature fluctuations are attenuated, thus eliminating the need to adjust for it. If humidity is not simultaneously measured in the cell but with an open-path sensor near the tube inlet, then:

$$
\left(\bar{P} / \bar{P}_{\mathrm{I}}\right)\left(\bar{T}_{\mathrm{I}} / \bar{T}\right) \overline{w^{\prime} \rho_{\nu 1}^{\prime}}=\overline{w^{\prime} \rho_{\nu}^{\prime}}+\left(\overline{\rho_{\nu}} / \bar{T}\right) \overline{w^{\prime} T^{\prime}}
$$

where $\bar{\rho}_{v}=\left(\bar{P} / \bar{P}_{\mathrm{I}}\right)\left(\bar{T}_{\mathrm{I}} / \bar{T}\right) \bar{\rho}_{v \mathrm{I}}$. (This relationship for water vapor flux is similar to Equation (11) derived for $\mathrm{CO}_{2}$ from Leuning and Moncrieff (1990).)

Then $F_{c}$ may be expressed by combining Equations (6) and (7) and noting that $\overline{\rho_{c}}=\left(\bar{P} / \bar{P}_{\mathrm{I}}\right)\left(\bar{T}_{\mathrm{I}} / \bar{T}\right) \bar{\rho}_{c \mathrm{I}}$ to yield (see Equations $(35 \mathrm{~b})$ and $(25)$, Webb et al., 1980):

$$
F_{c}=\left(\bar{P} / \bar{P}_{\mathrm{I}}\right)\left(\bar{T}_{\mathrm{I}} / \bar{T}\right)\left[\overline{w^{\prime} \rho_{c \mathrm{I}}^{\prime}}+\mu\left(\bar{\rho}_{c \mathrm{I}} / \bar{\rho}_{a}\right)\left(\overline{w^{\prime} \rho_{v}^{\prime}}+\left(\overline{\rho_{v}} / \bar{T}\right) \overline{w^{\prime} T^{\prime}}\right)\right] .
$$

The term involving $\overline{w^{\prime} T^{\prime}}$ is part of the WPL adjustment for the latent heat flux for the variation in air density due to the transport of sensible heat flux (see Equation (25) in Webb et al., 1980).

From Equations (6) and (8), it would follow that if the ambient air is brought to a constant temperature $\left(\bar{T}_{\mathrm{I}}\right)$, constant humidity $\left(\bar{\rho}_{v \mathrm{I}}\right.$ or dried so that $\left.\bar{\rho}_{v \mathrm{I}} \approx 0\right)$, and pressure $\left(\bar{P}_{1}\right)$ in the cell, the $\mathrm{CO}_{2}$ flux to a good approximation would be given as (e.g., Equations (18) and (20) in Webb et al., 1980):

$$
F_{c}=\left(\bar{P} / \bar{P}_{1}\right)\left(\bar{T}_{\mathrm{I}} / \bar{T}\right) \overline{w^{\prime} \rho_{c I}^{\prime}} .
$$

As seen in Equation (9), no WPL adjustment is required in this case.

\section{Method}

\subsection{SiTE AND CROP}

Micrometeorological measurements were made at the University of Nebraska's Agricultural Meteorological Laboratory $\left(41^{\circ} 09^{\prime} \mathrm{N}, 96^{\circ} 30^{\prime} \mathrm{W}, 354 \mathrm{~m}\right.$ above m.s.l.) approximately $10 \mathrm{~km}$ south of Mead, Nebraska during July and August, 1990. The field is relatively flat with a Sharpsburg silty clay loam soil (Typic Argiudall). 
Grain Sorghum (Sorghum bicolor L. Moench cv. DK-57) was planted on May 22, 1990 in $0.75 \mathrm{~m}$ north-south oriented rows. Sensors were placed at the north end of the field to maximize the upwind fetch for winds from the SE-SW $\left(135-225^{\circ}\right)$. The upwind fetch was greater than $200 \mathrm{~m}$.

\subsection{EDDY CORRELATION MEASUREMENTS}

Fluxes of $\mathrm{CO}_{2}$, latent and sensible heat were measured above the canopy with eddy correlation sensors mounted at a height of $2.5 \mathrm{~m}$. The sensor array consisted of a one-dimensional (vertical) sonic anemometer (Campbell and Unsworth, 1979), a fine wire $(0.025 \mathrm{~mm})$ thermocouple (Campbell Scientific, Logan, Utah, Model CA27-T), an open-path $\mathrm{CO}_{2}$ sensor with a $0.20 \mathrm{~m}$ path length (Advanced System Inc, Noda Okayama City, Japan, Model E-009, for details see Ohtaki and Matsui, 1982), and a closed-path $\mathrm{CO}_{2}$ sensor (LI-Cor Inc., Lincoln, Nebraska, Model LI6251). Signals from the eddy correlation instruments were low-pass filtered using 8-pole Butterworth active filters ( $12.5 \mathrm{~Hz}$ cutoff frequency) and sampled at $25 \mathrm{~Hz}$ with a 12 bit A/D converter (Data Translations, Marlboro, MA, DT2801). Data were recorded on optical disk using an Intel 80386-based IBM-compatible microcomputer. The $\mathrm{CO}_{2}$ sensors were calibrated twice on each day of measurements. Humidity sensors were calibrated prior to, once during, and then after the experiment.

\subsubsection{The Closed-Path $\mathrm{CO}_{2}$ Sensor}

The LI-6251 closed-path $\mathrm{CO}_{2}$ sensor is a differential, non-dispersive, infrared $\mathrm{CO}_{2}$ gas analyzer. Details of the sensor's operational theory are available from $\mathrm{Li}$ Cor Inc. (Li-Cor Manual publication number: 8712-56). The small sample cell $\left(0.6 \mathrm{~cm} \mathrm{H} \times 1.3 \mathrm{~cm} \mathrm{D} \times 15.2 \mathrm{~cm} \mathrm{~L}\right.$ or $\left.11.9 \mathrm{~cm}^{3}\right)$, the large flow rate possible through the cell $(\approx 10-15$ SLM, standard liters per minute), and the reasonably fast response time give this sensor potential to be adapted to eddy correlation measurements.

Figure 1 shows a schematic of the closed-path $\mathrm{CO}_{2}$ sensor. A valve-regulated vacuum pump (with ballast tank to damp mechanical pulses) pulls air through a stainless steel intake tube and particle filter, into the sample cell. The pump also pulls $\mathrm{CO}_{2}$ gas $(\approx 330 \mathrm{ppm})$ from a gas cylinder through the reference cell. The reference gas flow rate is regulated by a flow controller ( $\mathrm{J}$ and $\mathrm{W}$ Scientific, Folsom, CA). The flow rate is 0.04 SLM through the reference cell and up to 12 SLM through the sample cell, depending on flow configuration. At the outlet of the sample cell, mean air temperature is monitored using the factory installed thermistor. The gage pressure (pressure difference between ambient and sample cell outlet) and the pressure difference between the reference and sample cell outlets are monitored using pressure transducers (Omega Engineering Inc., Stamford, CT; Series PX143 and Series PX162). Gage pressure in the sample tube is typically $6.5 \mathrm{kPa}$ below ambient. The pressure difference between the sample and reference line is less than $0.1 \mathrm{kPa}$. Flowrates are monitored with rotameters. 


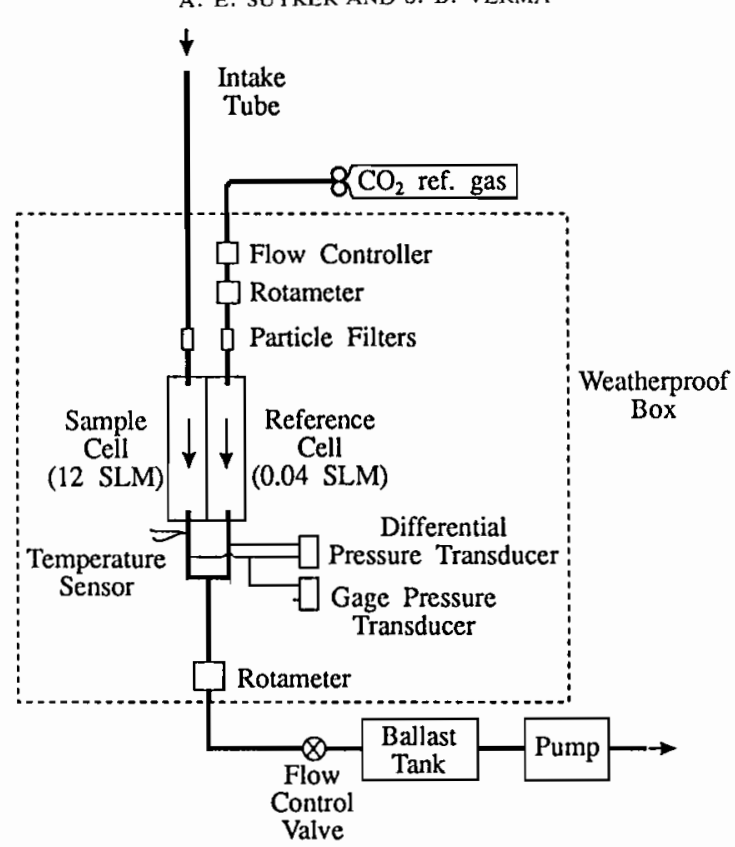

Fig. 1. Schematic of the closed-path $\mathrm{CO}_{2}$ system.

Time response $(\tau)$ of the sensor was estimated by introducing step changes in concentration just upstream of the particle filter at the instrument inlet. The physical components (e.g., particle filter, sample cell, connecting tubes) and the flow rate of air through the sample cell were assumed to be a simple first-order system. An exponential relationship was fit to the data to estimate $\tau$. Results indicate that $\tau \approx 0.05 \mathrm{~s}$. Delay time $(\approx 0.5-1.0 \mathrm{~s}$, depending on the flow configuration) was determined, based on a procedure described by McMillen (1988) and Chahuneau et al. (1988), by examining the cross-correlation of the $\mathrm{CO}_{2}$ signal with vertical velocity. To minimize the heat portion of the WPL adjustment, a stainless steel intake tube was used (Leuning and Moncrieff, 1990; Incropera and Dewitt, 1981).

\subsection{SuPPorting MiCROMETEOROLOGICAL MEASUREMENTS}

Dry and wet bulb temperatures were measured at 1.60 and $2.50 \mathrm{~m}$ with an exchanging system of aspirated ceramic wick psychrometers (Hartman and Gay, 1981). Mean windspeed was measured at $2.5 \mathrm{~m}$ using a cup anemometer (Cayuga Development, Ithaca, NY, Model WP-1). Wind direction was also monitored. Crop height was measured every 7 to 10 days.

\subsection{Computations of SPECTRA}

Spectra were calculated using Fast Fourier Transforms from a program adapted from Chahuneau et al. (1989). For the high frequency spectra, a one half-hour 
TABLE I

Tubeflow and attenuation parameters for the flow configurations tested. Information on tube length $(L)$, tube radius $(a)$, mean flow velocity $\left(u_{t}\right)$, flow rate $(Q)$, Reynolds number $(\mathrm{Re})$, attenuation coefficient $(\Lambda)$, and cutoff frequency $\left(n_{c}\right)$ is included

\begin{tabular}{|c|c|c|c|c|c|c|c|}
\hline $\begin{array}{l}\text { Tubeflow } \\
\text { Configuration }\end{array}$ & $\begin{array}{l}L \\
(\mathrm{~m})\end{array}$ & $\begin{array}{l}a \\
(\mathrm{~mm})\end{array}$ & $\begin{array}{l}u_{t} \\
\left(\mathrm{~m} \mathrm{~s}^{-1}\right)\end{array}$ & $\begin{array}{l}Q \\
(\mathrm{SLM})\end{array}$ & $\operatorname{Re}$ & $\Lambda$ & $\begin{array}{l}n_{c} \\
(\mathrm{~Hz})\end{array}$ \\
\hline I. Laminar flow & 3.0 & 3.11 & 4.1 & 7.5 & 1830 & 20.59 & 0.9 \\
\hline $\begin{array}{l}\text { II. Turbulent flow } \\
\text { (short intake) }\end{array}$ & 3.0 & 3.11 & 6.1 & 11.1 & 2710 & 9.23 & 2.0 \\
\hline $\begin{array}{l}\text { III. Turbulent flow } \\
\text { (longer intake) }\end{array}$ & 6.0 & 3.11 & 6.1 & 11.1 & 2710 & 9.23 & 1.1 \\
\hline $\begin{array}{l}\text { IV. Turbulent flow } \\
\text { (sub-sampling) }\end{array}$ & 3.0 & 4.70 & 7.2 & 30.0 & 4800 & 3.19 & 3.2 \\
\hline $\begin{array}{l}\text { V. Turbulent flow } \\
\text { (reduced } \\
\text { attenuation) }\end{array}$ & 3.0 & 2.72 & 7.1 & 9.9 & 2650 & 10.00 & 2.4 \\
\hline
\end{tabular}

data set (45000 points) was divided into ten blocks of 4096 points. The spectrum and cospectrum were calculated for each of these blocks. These ten spectra were averaged to produce the high frequency spectra. The low frequency spectra were computed from one set of 4096 points which was obtained by averaging the time series, ten points at a time, for the entire half-hour.

\section{Results and Discussion}

To study the effect of sampling air through an intake tube on $\mathrm{CO}_{2}$ fluxes, a range of tubeflow configurations (Table I) was field tested. Configurations I (laminar tubeflow) and II (turbulent tubeflow - short intake) have identical tube dimensions (diameter, $a$, and length, $L$ ) but different mean flow velocities, $u_{t}$ (and therefore different Reynolds numbers, $R e$, and attenuation coefficients, $\Lambda$ ). These configurations were used to examine tube attenuation effects in laminar and turbulent tubeflow conditions. The effect of changing intake tube length is examined in configuration III (turbulent tubeflow - longer intake). Configurations IV and V were employed to help develop recommendations to minimize the impact of tube sampling. In configuration IV, an alternate sampling method (sub-sampling) was studied. In this method, only a sample of air drawn from the intake tube (with a relatively large flow rate) passes through the closed-path sensor cell. This method may be useful if (a) the flow rate through the sensor needs to be small or (b) the intake tube flow rate needs to be large to reduce the attenuation effect of a long tube (e.g., see Zeller et al., 1989). Configuration V was an attempt to reduce the impact of tube attenuation without subsampling. Employing the turbulent tube attenuation model (Equations (1) and (2)), a tube diameter was selected to increase the tube attenuation cutoff frequency $\left(n_{c}\right)$ and mean flow velocity $\left(u_{t}\right)$ compared to configuration II at a lower flow rate $(Q \approx 10 \mathrm{SLM})$. 
TABLE II

Correction factors (CF) for laminar and turbulent tubeflow (configurations I and II) at two different heights ( $z$, above the zero plane) for a range of ambient horizontal windspeeds $(\bar{U})$

\begin{tabular}{|c|c|c|c|}
\hline$z=2 \mathrm{~m}$ & Correction factors & & \\
\hline $\begin{array}{l}\bar{U} \\
\left(\mathrm{~m} \mathrm{~s}^{-1}\right)\end{array}$ & $\begin{array}{l}\text { Configuration I } \\
\text { Laminal tubeflow } \\
\text { (time response and tube } \\
\text { attenuation) }\end{array}$ & $\begin{array}{l}\text { Configuration II } \\
\text { Turbulent tubeflow } \\
\text { (time response and tube } \\
\text { attenuation) }\end{array}$ & $\begin{array}{l}\text { Time response only } \\
(\Lambda=0)\end{array}$ \\
\hline 1.0 & 1.05 & 1.02 & 1.01 \\
\hline 3.0 & 1.16 & 1.08 & 1.04 \\
\hline 5.0 & 1.26 & 1.13 & 1.06 \\
\hline 7.0 & 1.36 & 1.17 & 1.08 \\
\hline$z=4 \mathrm{~m}$ & Correction factors & & \\
\hline $\begin{array}{l}\bar{U} \\
\left(\mathrm{~m} \mathrm{~s}^{-1}\right)\end{array}$ & $\begin{array}{l}\text { Configuration I } \\
\text { Laminar tubeflow } \\
\text { (time response and tube } \\
\text { attenuation) }\end{array}$ & $\begin{array}{l}\text { Configuration II } \\
\text { Turbulent tubeflow } \\
\text { (time response and tube } \\
\text { attenuation) }\end{array}$ & $\begin{array}{l}\text { Time response only } \\
(\Lambda=0)\end{array}$ \\
\hline 1.0 & 1.02 & 1.01 & 1.01 \\
\hline 3.0 & 1.08 & 1.03 & 1.02 \\
\hline 5.0 & 1.13 & 1.06 & 1.03 \\
\hline 7.0 & 1.19 & 1.09 & 1.04 \\
\hline
\end{tabular}

\subsection{Theoretical analysis of FluX loss due to tube attenuation AND TIME RESPONSE}

The loss of flux due to tube attenuation and inadequate time response for a given tubeflow configuration can be expressed by a correction factor, CF, computed following a procedure by Moore (1986):

$$
\mathrm{CF}=\int_{0}^{\infty} C_{w \rho_{c}}(n) \mathrm{d} n / \int_{0}^{\infty} C_{w \rho_{\mathrm{c}}}(n) G(n) T_{t}(n) \mathrm{d} n,
$$

where $C_{w \rho_{c}}(n)$ is the cospectrum of $w$ and $\rho_{c}$ at frequency $n(\mathrm{~Hz})$, and $G(n)$ is the time response transfer function. The term $T_{t}(n)$ is the tube attenuation transfer function (Equation (1) with (2) or (3) - Massman, 1991 or Philip, 1963c). Tube attenuation parameters $\left(L, a, u_{t}, \Lambda\right)$, time response $(\tau)$, sampling height and mean ambient windspeed are required to calculate $\mathrm{CF}$ when comparing the flux loss for different tubeflow configurations. Equation (10) was used to evaluate $\mathrm{CF}$ for typical laminar and turbulent tubeflow configurations (I and II) at two heights and a range of windspeeds under unstable conditions (Table II).

At a height $z$ (above the zero plane) of $2 \mathrm{~m}$ for ambient mean windspeed $(\bar{U})$ varying from 1 to $7 \mathrm{~m} \mathrm{~s}^{-1}$, CF ranged from 1.05 to 1.36 for laminar tubeflow and from 1.02 to 1.17 for turbulent tubeflow. The correction is consistently greater for laminar tubeflow. This is because, compared to the relatively uniform velocity profile in turbulent tubeflow, the parabolic laminar velocity profile causes more 
longitudinal dispersion and hence more attenuation as the air flows through the tube (e.g., Lenschow and Raupach, 1991). The value of CF for a given tubeflow is also influenced by the mean windspeed. Consideration of a logarithmic cospectrum graph of a scalar (e.g., Figure 4 in Kaimal et al., 1972) indicates that an increase in $\bar{U}$ would cause a decrease in the nondimensionalized tube attenuation cutoff frequency, $f_{c}=n_{c} z / \bar{U}$, resulting in an increased loss of flux due to signal attenuation in the tube. Similarly, an increase in $z$ from 2 to $4 \mathrm{~m}$ (Table II) reduced CF due to an increase in $f_{c}$.

To separate the effect of time response from that of tube attenuation, values of CF were calculated with $\Lambda=0$ (Table II). At $z=2 \mathrm{~m}$ and for $\bar{U}=1 \mathrm{~m} \mathrm{~s}^{-1}$ for example, $\mathrm{CF}$ for time response alone was 1.01. There was a slight increase in $\mathrm{CF}$ (up to a few percent) with laminar or turbulent tube attenuation included in the calculation. However, for $\bar{U}=7 \mathrm{~m} \mathrm{~s}^{-1}$ at the same height, the effect of attenuation in laminar tubeflows increased CF from 1.08 to 1.36 . At $z=4 \mathrm{~m}$ in turbulent tubeflows, including the tube attenuation effect, caused virtually no change in $\mathrm{CF}$ at $\bar{U}=1 \mathrm{~m} \mathrm{~s}^{-1}$. At $\bar{U}=5 \mathrm{~m} \mathrm{~s}^{-1}$ however, the value of CF increased from 1.03 to 1.06. These examples indicate that there are some tubeflow configurations or windspeeds/measurement heights where tube attenuation does not significantly affect the frequency response correction. There are, however, other situations where the impact could be significant.

The correction factors given in Table II do not account for the effect of the undeveloped flow velocity profile in the entrance of the intake tube. Data from Lenschow and Raupach (1991) show that the tube attenuation for undeveloped flows is less than that for fully developed flows. Thus, the calculations using the entire length of the tube would overcorrect the attenuation effect. In laminar tubeflows, where the entrance length would be long, the effect could be significant. The values of CF for laminar tubeflow in Table II, therefore, may be overestimated somewhat.

\subsection{Field MEAsurements USing Closed- AND open-Path SENSORS}

\subsection{1. $\mathrm{CO}_{2}$ Cospectrum}

Figures 2 and 3 show normalized cospectrum $\left(n C_{w \rho_{c}}(n) / \overline{w^{\prime} \rho_{c}^{\prime}}\right)$ of $\mathrm{CO}_{2}$ (measured using closed- and open-path sensors) plotted against the dimensionless frequency $(f=n z / \bar{U})$. The closed-path cospectra for typical laminar (configuration I) and turbulent (configuration II) tubeflows are shown. Theoretical cospectrum ${ }^{3}$ for a scalar (Kaimal et al., 1972) is also shown.

The cospectrum from the open-path sensor (Figures 2 and 3 ) is in good agreement with the theoretical cospectrum. There is a slight rolloff from the theoretical $-2 / 3$ slope in the inertial subrange, beginning at $f \approx 2.5$, probably due to volume averaging. The cospectrum measured with the closed-path sensor shows good agreement with the theory for lower frequencies (up to $f=0.4$ for configuration I and $f=0.6$ for configuration II) as shown in Figures 2 and 3 . The closed-path

\footnotetext{
${ }^{3}$ The cospectral expressions derived using a non-linear least squares fit to data from the Kansas experiments (Kaimal et al., 1973, Equations (21a, b) and (25)) are referred to as theoretical.
} 


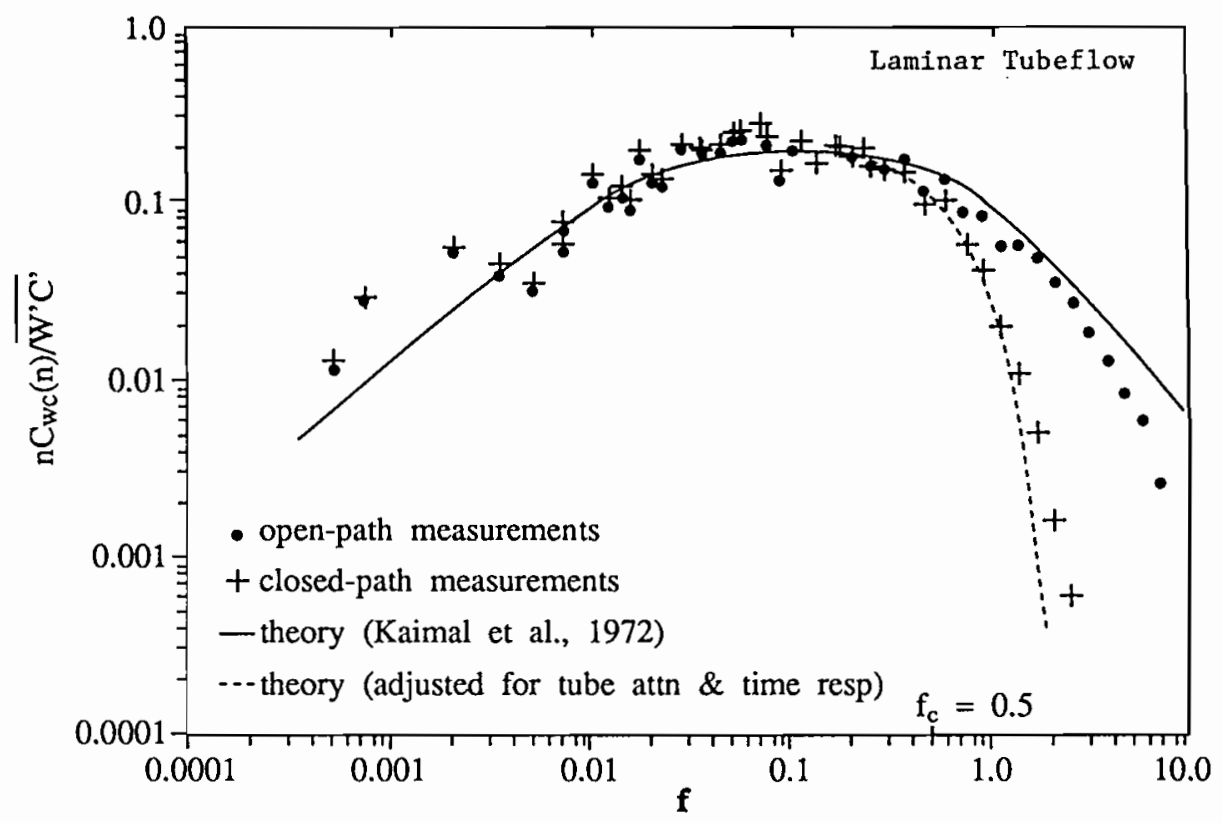

Fig. 2. Normalized logarithmic cospectra $\left(n C_{w \rho}(n) / \overline{w^{\prime} \rho_{c}^{\prime}}\right)$ of $\mathrm{CO}_{2}$ flux as a function of dimensionless frequency $(f=n z / \bar{U})$. Included are cospectra measured with the open- and closed-path sensors, theoretical cospectrum for a scalar (Kaimal et al., 1972), the adjusted theoretical cospectrum (see Section 4.2.1 for details), and the cutoff frequency $\left(f_{c}\right)$ for laminar tubeflow (configuration I). August 7, 1990: 15:00-15:30 hr (local time). $z=1.7 \mathrm{~m}$ and $\bar{U}=2.8 \mathrm{~m} \mathrm{~s}^{-1}$.

cospectra exhibit rapid signal attenuation at higher frequencies. Also plotted is an "adjusted" theoretical cospectrum (i.e., the integrand of the denominator of Equation (10) normalized by the covariance) using the appropriate tube attenuation and time response parameters $\left(L, a, u_{t}, \Lambda\right.$, and $\left.\tau\right)$ given in Table I. The measured closed-path cospectrum agrees reasonably with the adjusted theoretical cospectrum for both configurations. Although inadequate time response contributes to the rolloff, the observed rapid attenuation for $f>f_{c}(=0.5$ and 0.8 for the laminar and turbulent tubeflow, respectively) is primarily due to the frequency squared dependency of the tube attenuation transfer function (Section 2.1).

The theoretical adjustment in the laminar tubeflow (configuration I, Figure 2) overcorrects the measured signal attenuation. This is likely, in part, due to the entrance region effect as was discussed in Section 4.1. The difference between measured and theoretically adjusted cospectra for higher frequencies in the turbulent tubeflow configuration (configuration II, Figure 3 ) could possibly be due to volume averaging or lateral sensor separation. If the entrance region effect were accounted for, the difference in these cospectra could be larger. The effect on $\mathrm{CO}_{2}$ flux would be small, however. 


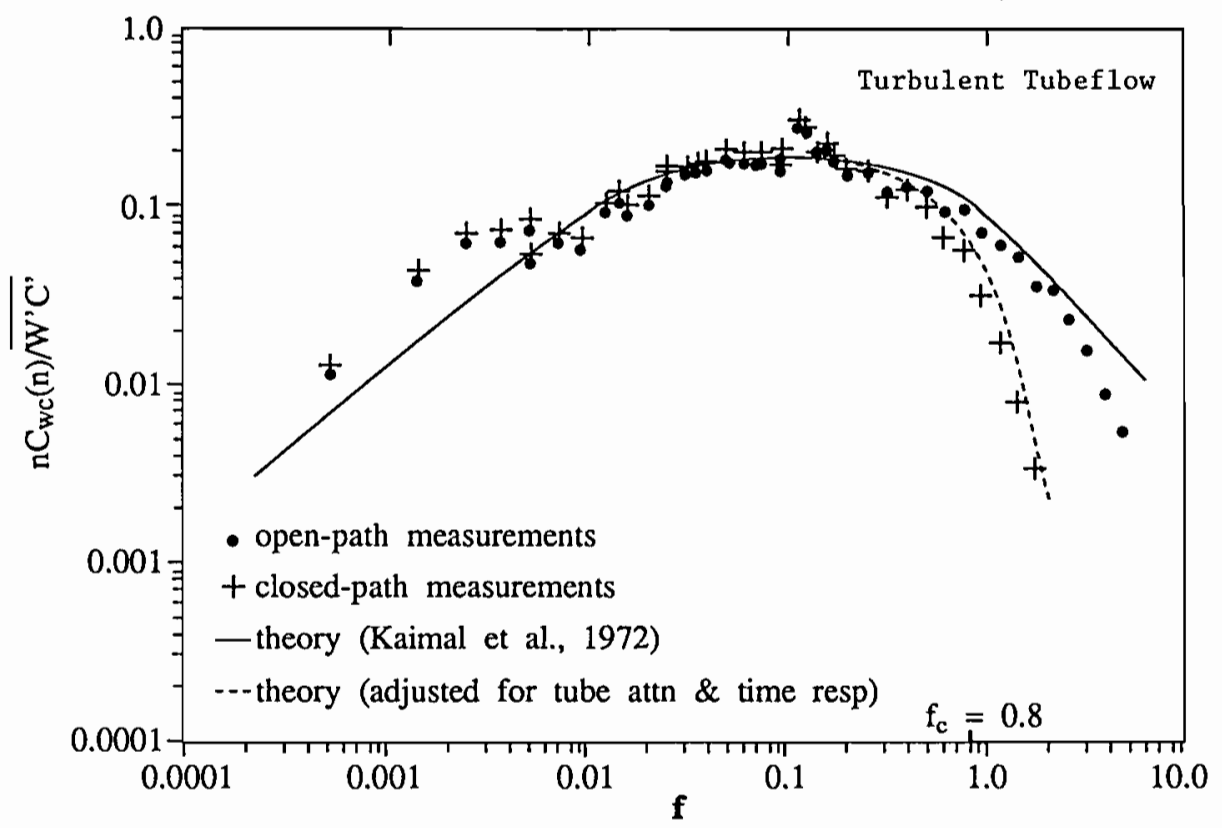

Fig. 3. Normalized logarithmic cospectra $\left(n C_{w \rho}(n) / \overline{w^{\prime} \rho_{c}^{\prime}}\right)$ of $\mathrm{CO}_{2}$ flux as a function of dimensionless frequency $(f=n z / \bar{U})$. Included are cospectra measured with the open- and closed-path sensors, theoretical cospectrum for a scalar (Kaimal et al., 1972), the adjusted theoretical cospectrum (see Section 4.2 .1 for details), and the cutoff frequency $\left(f_{c}\right)$ for turbulent tubeflow (configuration II). August $17,1990: 12: 30-13: 00 \mathrm{hr}$ (local time), $z=1.7 \mathrm{~m}$ and $\bar{U}=3.9 \mathrm{~m} \mathrm{~s}^{-1}$.

\subsection{2. $\mathrm{CO}_{2}$ Flux}

Raw values of $\mathrm{CO}_{2}$ fluxes ${ }^{4}$ (averaged over 30 min time periods) for each tubeflow configuration are compared with those measured using the open-path sensor (Figure 4). Included are slopes and regression coefficients $\left(r^{2}\right)$ calculated from the least squares fit of the data. The open-path flux measurement was used as the independent variable (or standard of comparison).

The raw $\mathrm{CO}_{2}$ flux measured with the closed-path sensor was smaller by about $24 \%$ (on average) in laminar tubeflow (configuration I). The raw flux in the turbulent tubeflow with a short intake tube (configuration II) was smaller by about $16 \%$, and by about $31 \%$ for the longer intake tube (configuration III). Laminar tubeflow and a long intake tube seem to increase the difference greatly. In configurations IV and $\mathrm{V}$, the raw flux was smaller by about 15 and $16 \%$, respectively, suggesting that these configurations did not reduce the tube attenuation compared to II. However, as was alluded to in Section 4.1, variations in ambient windspeed could mask the impact of the different configurations.

Appropriate frequency response corrections and WPL adjustments were applied

${ }^{4}$ The sign convention used here is such that fluxes to the surface are positive. 


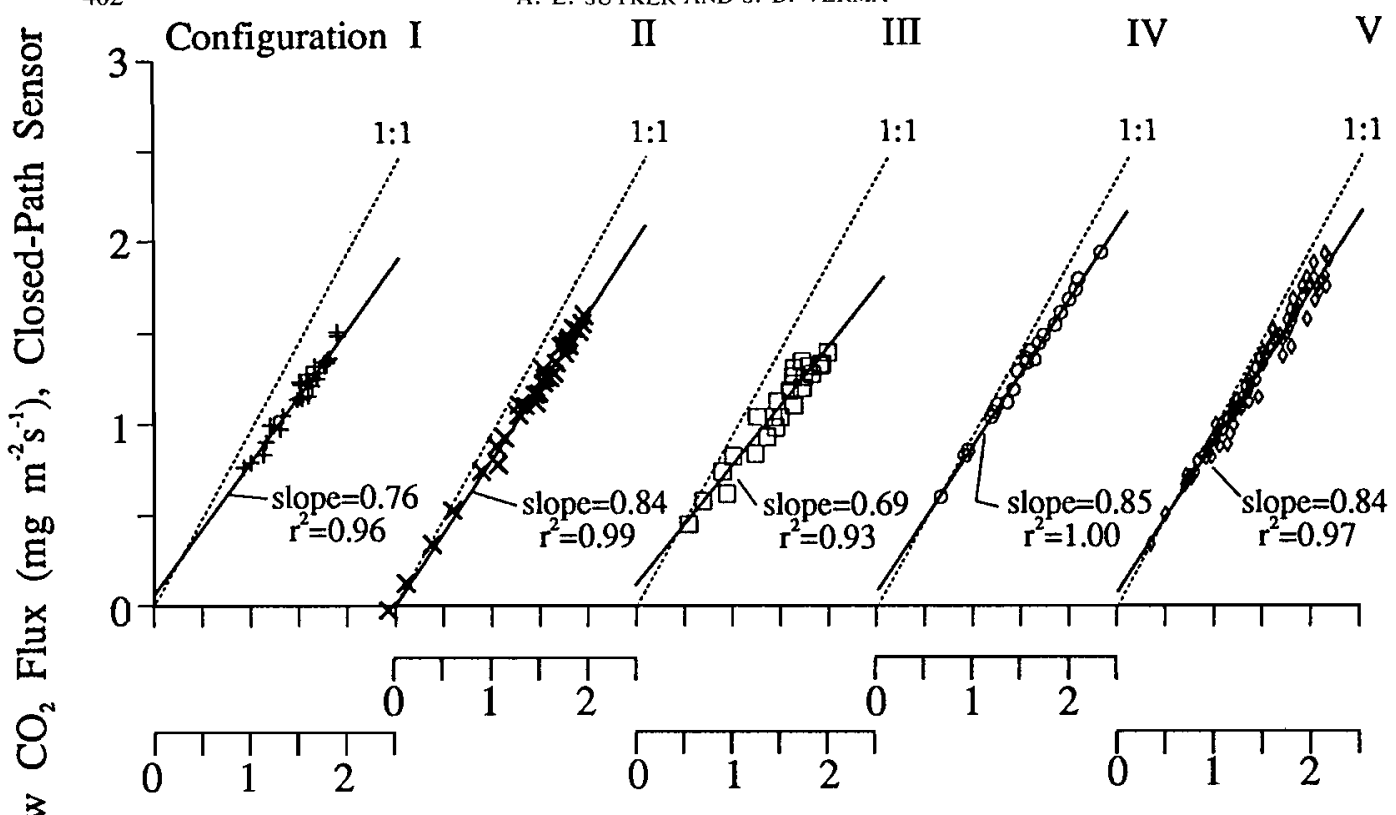

Raw $\mathrm{CO}_{2}$ Flux $\left(\mathrm{mg} \mathrm{m}^{-2} \mathrm{~s}^{-1}\right)$, Open-Path Sensor

Fig. 4. Raw values of $\mathrm{CO}_{2}$ fluxes measured using the closed-path sensor compared with those measured using the open-path sensor for configuration I (laminar tubeflow), II (turbulent-short intake), III (turbulent-longer intake), IV (sub-sampling) and V (turbulent-reduced attenuation). The dotted and solid lines represent $1: 1$ and linear regression equations respectively.

to raw fluxes measured with closed- and open-path sensors. $\mathrm{CO}_{2}$ fluxes so corrected are shown in Figure 5. The corrected flux in laminar tubeflow (configuration I) was overestimated by about $12 \%$. This may, in part, be the effect of ignoring the entrance region. The corrected flux in the turbulent tubeflow with the short intake tube (configuration II) shows an overestimation of about $4 \%$ (Figure 5). The corrected fluxes for configuration III (turbulent tubeflow - longer intake) and configuration $\mathrm{V}$ (turbulent tubeflow - reduced attenuation) show an underestimation of about $1 \%$. Sub-sampling in configuration IV shows an overestimation of about $5 \%$. The tube attenuation model and the WPL adjustment consistently seem to work well in correcting the $\mathrm{CO}_{2}$ fluxes measured with the closed-path sensor. Differences in raw data as large as $31 \%$ have been reduced to only a few percent except for the case of laminar tubeflow.

It may be worthwhile to note the contributions of tube attenuation of $\mathrm{CO}_{2}$ density and temperature fluctuations to the difference in raw fluxes measured with the closed-path sensor. Table III shows a few examples of raw fluxes and those corrected for frequency response. The frequency response-corrected fluxes from the closed- and open-path $\mathrm{CO}_{2}$ sensors on day 205 agreed within about $0.05 \mathrm{mg} \mathrm{m}^{-2} \mathrm{~s}^{-1}(\approx 4 \%)$, implying that tube attenuation accounted for most of the raw flux difference. On day 234 however, the frequency response-corrected fluxes 


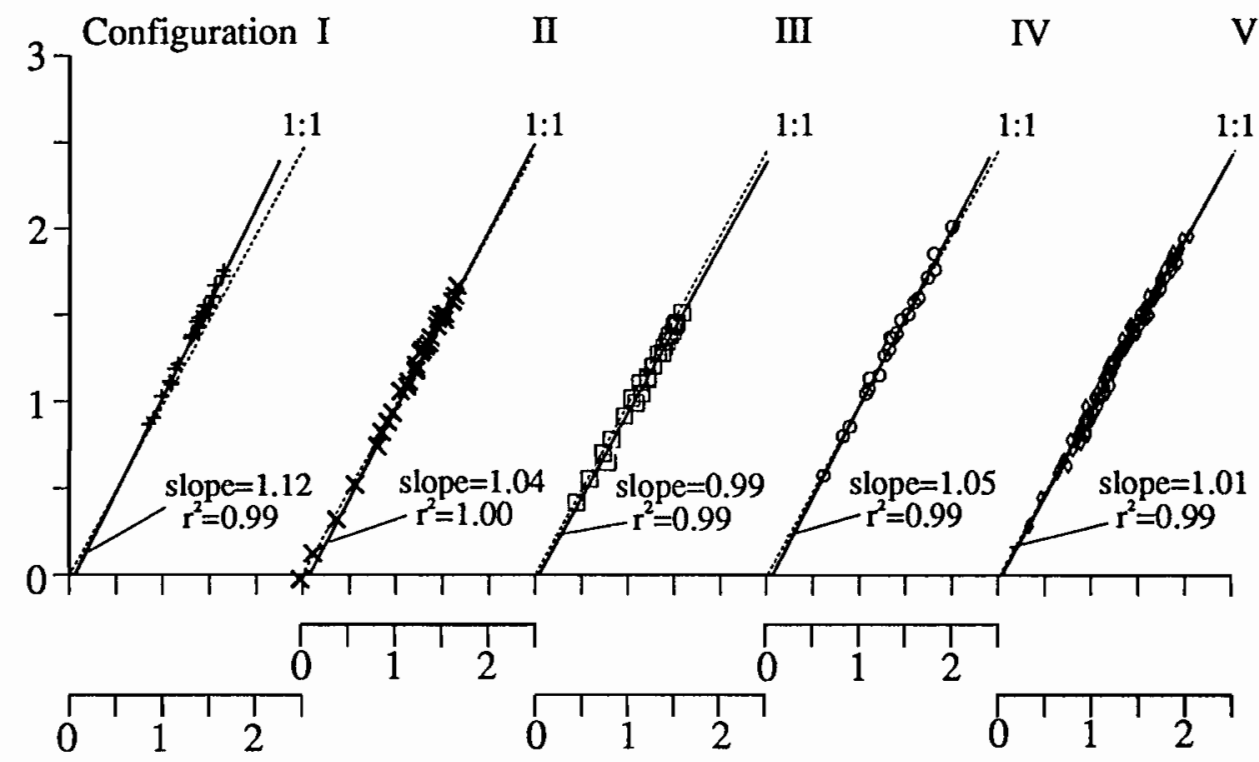

\section{Corrected $\mathrm{CO}_{2}$ Flux ( $\mathrm{mg} \mathrm{m} \mathrm{m}^{-2} \mathrm{~s}^{-1}$ ), Open-Path Sensor}

Fig. 5. Corrected values of $\mathrm{CO}_{2}$ fluxes measured using the closed-path sensor compared with those measured using the open-path sensor for configuration I (laminar tubeflow), II (turbulent-short intake), III (turbulent-longer intake), IV (sub-sampling) and V (turbulent-reduced attenuation). The dotted and solid lines represent 1:1 and linear regression equations, respectively.

differ by 0.27 to $0.31 \mathrm{mg} \mathrm{m}^{-2} \mathrm{~s}^{-1}$ (or about $15 \%$ ). The source of the flux difference between frequency response-corrected data can be examined by equating the righthand expressions of $F_{c}$ from the open- and closed-path sensors (Equations (5) and (8) assuming $\bar{P} \bar{T}_{\mathrm{I}} / \bar{P}_{\mathrm{I}} \bar{T} \approx 1$ for simplicity, i.e., sample cell temperature and pressure similar to ambient pressure and mean temperature such that $\overline{\rho_{c}}=\overline{\rho_{C I}}$ ) to yield:

$$
\overline{w^{\prime} \rho_{c l}^{\prime}}=\overline{w^{\prime} \rho_{c}^{\prime}}+\left(\overline{\rho_{c}} / \bar{T}\right) \overline{w^{\prime} T^{\prime}} \text {. }
$$

Equation (11) indicates that the difference between closed- and open-path raw fluxes also depends on the ambient heat flux (note that $\overline{w^{\prime} T^{\prime}}<0$ ). This heat flux is absorbed into the tubewall as $T^{\prime}$ is attenuated, thereby causing a corresponding change in the raw $\mathrm{CO}_{2}$ flux measured with a closed-path sensor. The theoretical difference term, $\left(\overline{\rho_{c}} / \bar{T}\right) \overline{w^{\prime} T^{\prime}}$, which is a significant portion of the open-path $\mathrm{CO}_{2}$ flux adjustment for the simultaneous transfer of sensible heat, is also shown in Table III. The $\left(\overline{\rho_{c}} / \bar{T}\right) \overline{w^{\prime} T^{\prime}}$ term seems to agree reasonably well with the difference in frequency response-corrected $\mathrm{CO}_{2}$ fluxes. The largest differences in these fluxes correspond to periods with large values of sensible heat flux $\left(-119\right.$ to $-176 \mathrm{~W} \mathrm{~m}^{-2}$, day 234). On day 205, the sensible heat flux was small $\left(5\right.$ to $\left.8 \mathrm{~W} \mathrm{~m}^{-2}\right)$ and the frequency response-corrected $\mathrm{CO}_{2}$ fluxes were close. The attenuation of tempera- 
TABLE III

$\mathrm{CO}_{2}$ fluxes (raw and frequency response-corrected) for selected time periods for configurations II, III, IV, and $\mathrm{V}$

\begin{tabular}{|c|c|c|c|c|c|c|c|c|c|c|}
\hline \multirow[t]{2}{*}{$\begin{array}{l}\text { Tubeflow } \\
\text { configuration }\end{array}$} & \multirow[t]{2}{*}{$\begin{array}{l}\text { Day } \\
\text { of } \\
\text { year }\end{array}$} & \multirow[t]{2}{*}{$\begin{array}{l}\text { Mid- } \\
\text { time }\end{array}$} & \multicolumn{3}{|c|}{$\begin{array}{l}\text { Raw } \mathrm{CO}_{2} \text { flux } \\
\left(\mathrm{mg} \mathrm{m}^{-2} \mathrm{~s}^{-1}\right)\end{array}$} & \multicolumn{3}{|c|}{$\begin{array}{l}\mathrm{CO}_{2} \text { flux corrected for } \\
\text { frequency response } \\
\left(\mathrm{mg} \mathrm{m}^{-2} \mathrm{~s}^{-1}\right)\end{array}$} & \multirow[t]{2}{*}{$\begin{array}{l}\text { Heat } \\
\text { flux } \\
\left(\mathrm{W} \mathrm{m}^{-2}\right)\end{array}$} & \multirow[t]{2}{*}{$\begin{array}{l}\left(\overline{\rho_{c}} / \bar{T}\right) \overline{w^{\prime} T^{\prime}} \\
\left(\mathrm{mg} \mathrm{m}^{-2} \mathrm{~s}^{-1}\right)\end{array}$} \\
\hline & & & $\begin{array}{l}\text { Closed } \\
\text { path }\end{array}$ & $\begin{array}{l}\text { Open } \\
\text { path }\end{array}$ & Diff. & $\begin{array}{l}\text { Closed } \\
\text { path }\end{array}$ & $\begin{array}{l}\text { Open } \\
\text { path }\end{array}$ & Diff. & & \\
\hline \multirow{4}{*}{$\begin{array}{l}\text { II. Turbulent flow } \\
\text { (short intake) }\end{array}$} & 229 & $12: 45$ & 1.49 & 1.72 & -0.23 & 1.68 & 1.76 & -0.08 & -79 & -0.11 \\
\hline & 229 & $13: 15$ & 1.47 & 1.68 & -0.21 & 1.65 & 1.71 & -0.06 & -68 & -0.10 \\
\hline & 229 & $13: 45$ & 1.46 & 1.65 & -0.19 & 1.65 & 1.69 & -0.03 & -58 & -0.08 \\
\hline & 229 & $14: 15$ & 1.28 & 1.48 & -0.20 & 1.47 & 1.51 & -0.04 & -45 & -0.06 \\
\hline \multirow{4}{*}{$\begin{array}{l}\text { III. Turbulent flow } \\
\text { (longer intake) }\end{array}$} & 234 & $12: 45$ & 1.41 & 1.90 & -0.49 & 1.63 & 1.94 & -0.31 & -176 & -0.25 \\
\hline & 234 & $13: 15$ & 1.35 & 1.85 & -0.50 & 1.58 & 1.89 & -0.31 & -154 & -0.22 \\
\hline & 234 & $13: 45$ & 1.34 & 1.83 & -0.49 & 1.58 & 1.88 & -0.30 & -188 & -0.26 \\
\hline & 234 & $14: 15$ & 1.30 & 1.75 & -0.45 & 1.52 & 1.79 & -0.27 & -119 & -0.17 \\
\hline \multirow{3}{*}{$\begin{array}{l}\text { IV. Turbulent flow } \\
\text { (sub-sampling) }\end{array}$} & 205 & $16: 15$ & 1.05 & 1.14 & -0.09 & 1.16 & 1.16 & 0.0 & 8 & 0.01 \\
\hline & 205 & $16: 45$ & 1.14 & 1.28 & -0.14 & 1.27 & 1.31 & -0.04 & 5 & 0.01 \\
\hline & 205 & $17: 15$ & 1.12 & 1.18 & -0.06 & 1.25 & 1.20 & 0.05 & 8 & 0.01 \\
\hline \multirow{6}{*}{$\begin{array}{l}\text { V. Turbulent flow } \\
\text { (reduced } \\
\text { attenuation) }\end{array}$} & 96 & $10: 45$ & 1.44 & 1.59 & -0.15 & 1.56 & 1.62 & -0.06 & -43 & -0.06 \\
\hline & 196 & $11: 15$ & 1.38 & 1.51 & -0.13 & 1.50 & 1.54 & -0.04 & -39 & -0.05 \\
\hline & 196 & $11: 45$ & 1.39 & 1.56 & -0.17 & 1.51 & 1.58 & -0.07 & -28 & -0.04 \\
\hline & 198 & $12: 45$ & 1.72 & 2.08 & -0.36 & 1.95 & 2.11 & -0.14 & -66 & -0.09 \\
\hline & 198 & $13: 15$ & 1.68 & 2.03 & -0.35 & 1.91 & 2.06 & -0.15 & -59 & -0.08 \\
\hline & 198 & $13: 45$ & 1.80 & 2.13 & -0.33 & 2.03 & 2.16 & -0.13 & -55 & -0.08 \\
\hline
\end{tabular}

ture in the tube, therefore, can have a significant impact on the difference between raw fluxes measured with closed- and open-path sensors. This attenuation eliminates the need to correct raw closed-path fluxes for density effects from the simultaneous transfer of sensible heat.

\subsection{Optimum tubeflow CONFIGURATION: Minimizing tUbE attenUATION}

In choosing an optimum configuration, consideration must be given to maximizing the nondimensional cutoff frequency $\left(f_{c}\right)$. Caution must be exercised to avoid an excessively large mean flow velocity $\left(u_{t}\right)$, which can distort the flow around the velocity sensor. To minimize tube attenuation effects, turbulent tubeflow is preferred. Turbulent tubeflow also provides the advantage of a short entrance length region.

The first step is to consider the maximum possible flow rate through the analyzer and an initial tube diameter that will generate turbulent tubeflow. The mean flow velocity $\left(u_{t}\right)$ and Reynolds number $(\mathrm{Re})$ should be calculated and the attenuation coefficient $(\Lambda)$ taken from Massman (1991). The cutoff frequency $\left(f_{c}\right)$ should then be calculated (Equation (4) with $\left.f_{c}=n_{c} z / \bar{U}\right)$ using expected heights $(z)$, mean windspeeds $(\bar{U})$, and an estimate of the tube length $(L)$. Both $f_{c}$ and $u_{t}$ should be calculated for a range of tube diameters (a). Based on acceptable values of $u_{t}$, an optimum $f_{c}$ (and hence tube diameter) should be selected.

Tube length should, of course, be kept to a minimum. In cases where the tube 
length will need to be long ( $L>5 \mathrm{~m}$ ) or if the tube Reynolds numbers would be laminar due to a low flow rate through the sample cell, sub-sampling should be considered to maintain turbulent tubeflow in the intake tube. When choosing tube parameters for sub-sampling, a similar procedure as described above would be necessary. However, for this configuration both the tube diameter and flow rate through the intake tube may be varied to choose the optimum configuration.

Consideration should also be given to the sensor's time response. For poor time response (and depending on factors such as $z$ and $\bar{U}$ ), tube attenuation may have virtually no impact on the loss in flux. In such cases, choosing parameters to minimize tube attenuation would not be as important.

\section{Summary and Conclusions}

A closed-path sensor employing several intake tube configurations was used to make eddy correlation measurements of $\mathrm{CO}_{2}$ flux. An open-path sensor was used as a standard of comparison. Sampling air through an intake tube partially attenuates $\mathrm{CO}_{2}$ density fluctuations causing a loss in flux. This loss may be estimated using models by Massman (1991) for turbulent tubeflow and by Philip (1963c) for laminar tubeflow.

The raw flux measured with the closed-path sensor was smaller by 15 to $31 \%$. The difference was largest ( 24 and $31 \%$ ) in configuration I (laminar tubeflow) and configuration III (turbulent tubeflow - longer intake tube). The fluxes measured in configurations II, IV, and V (other turbulent tubeflows) were smaller by about $15 \%$. These differences resulted from (a) the attenuation of $\mathrm{CO}_{2}$ density fluctuations in the tube, (b) inadequate time response, and (c) the absorption of ambient heat flux into the tubewall.

The raw $\mathrm{CO}_{2}$ fluxes from both sensors were corrected for frequency response and for density effects. With these corrections, the closed- and open-path fluxes agreed to within a few percent $(<5 \%)$ for all configurations except for configuration I (laminar tubeflow). The closed-path flux overestimated the open-path flux by about $12 \%$ in the laminar tubeflow. This may, in part, have resulted because the entrance length effect was ignored.

\section{Acknowledgements}

This study was supported by the National Science Foundation under Grant ATM9006327 and by the University of Nebraska Center for Laser-Analytical Studies in Trace Gas Dynamics. Special thanks to Drs. William Massman, Donald Lenschow and John Moncrieff for their valuable assistance with tube attenuation theory and for their review of this manuscript. Messrs. H. D. Earl and Sheldon Sharp provided assistance in maintenance of instruments and data acquisition systems. Mr. James Hines assisted in data computation. We thank Dr. Joon Kim and Mr. Rob Clement for their assistance and advice in data collection and 
processing and for their review of this manuscript, Mrs. Sharon Kelly for typing the manuscript, and Ms. Sheila Smith for preparing the figures.

\section{References}

Baldocchi, D. D., Hicks, B. B., and Meyers, T. P.: 1988, 'Measuring Biosphere-Atmosphere Exchanges of Biologically Related Gases with Micrometeorological Methods', Ecology 69, 1331-1340.

Barton, N. G.: 1983, 'The Dispersion of Solute from Time-Dependent Releases in Parallel Flow', $J$. Fluid Mech. 136, 243-267.

Businger, J. A.: 1986, 'Evaluating the Accuracy with which Dry Deposition Can be Measured with Current Micrometeorological Techniques', J. Clim. Appl. Meteorol. 25, 1100-1124.

Campbell, G. S. and Unsworth, M. H.: 1979, 'An Inexpensive Sonic Anemometer for Eddy Correlation', J. Appl. Meteorol. 18, 1072-1077.

Chahuneau, F., Desjardins, R. L., Brach, E., and Verdon, R.: 1989, 'A Micrometeorological Facility for Eddy Flux Measurements of $\mathrm{CO}_{2}$ and $\mathrm{H}_{2} \mathrm{O}$ ', J. Atmos. Oceanic Technol. 6, 193-200.

Fan, S., Wofsy, S. C., Bakwin, P. S., and Jacob, D. J.: 1990, 'Atmosphere-Biosphere Exchange of $\mathrm{CO}_{2}$ and $\mathrm{O}_{3}$ in the Central Amazon Forest', J. Geophys. Res. 95, 16851-16864.

Hartman, R. K. and Gay, L. W.: 1981, 'Improvements in the Design and Calibration of Temperature Measurement Systems', in Proc., 15th Conf. Agric. For. Meteorol. 210 pp.

Hicks, B. B., Wesley, M. L., Coultier, R. L., Hart, R. L., Durham, J. L., Speer, R., and Stedman, D. H.: 1986, 'An Experimental Study of Sulphur and $\mathrm{NO}_{x}$ Fluxes Over Grassland', Boundary-Layer Meteorol. 34, 103-121.

Incropera, F. P. and DeWitt, D. P.: 1981, Fundamentals of Heat and Mass Transfer, 2nd ed., John Wiley and Sons Inc., New York.

Kaimal, J. C., Wyngaard, J. C., Izumi, Y., and Cote, O. R.: 1972, 'Spectral Characteristics of SurfaceLayer Turbulence', Quart. J. Roy. Meteorol. Soc. 98, 563-589.

Lenschow, D. and Raupach, M.: 1991, 'The Attenuation of Fluctuations in Scalar Concentrations Through Sampling Tubes', J. Geophys. Res. 96, 15259-15268.

Leuning, R. and Moncrieff, J.: 1990, 'Eddy Covariance $\mathrm{CO}_{2}$ Flux Measurements Using Open- and Closed-Path $\mathrm{CO}_{2}$ Analysers: Corrections for Analyser Water Vapor Sensitivity and Damping of Fluctuations in Air Sampling Tubes', Boundary-Layer Meteorol. 53, 63-76.

Massman, W. J.: 1991, 'The Attenuation of Concentration Fluctuations in Turbulent Flow in a Tube', J. Geophys. Res. 96, 15269-15273.

McMillen, R. T.: 1988, 'An Eddy Correlation Technique with Extended Applicability to Non-Simple Terrain', Boundary-Layer Meteorol. 43, 231-245.

Moore, C. J.: 1986, 'Frequency Response Corrections for Eddy Correlation Systems', Boundary-Layer Meteorol. 37, 17-35.

Ohtaki, E. and Matsui, M.: 1982, 'Infra-Red Device for Simultaneous Measurement of Atmospheric Carbon Dioxide and Water Vapor', Boundary-Layer Meteorol. 24, 109-119.

Philip, J. R.: 1963a, 'The Theory of Dispersal during Laminar Flow in Tubes, I', Aust. J. Phys. 16, 287-299.

Philip, J. R.: 1963b, 'The Theory of Dispersal during Laminar Flow in Tubes, II', Aust. J. Phys. 16, 300-310.

Philip, J. R.: 1963c, 'The Damping of a Fluctuating Concentration by Continuous Sampling Through a Tube', Aust. J. Phys. 16, 454-463.

Taylor, G. I.: 1953, 'Dispersion of Soluble Matter in Solvent Flowing Through a Tube', Proc. R. Soc. London, Ser. A 219, 186-203.

Taylor, G. I.: 1954, 'The Dispersion of Matter in Turbulent Flow Through a Pipe', Proc. $R$. Soc. London, Ser. A 223, 446-468.

Verma, S. B.: 1990, 'Micrometeorological Methods for Measuring Surface Fluxes', Remote Sens. Rev. $5,99-115$.

Webb, E. K., Pearman, G. I. and Leuning, R.: 1980, 'Correction of Flux Measurements for Density Effects Due to Heat and Water Vapor Transfer', Quart. J. Roy. Meteorol. Soc. 106, 85-100. 
Wesley, M. L., Eastman, D. R., Cook, D. R., and Hicks, B. B.: 1978, 'Daytime Variations of Ozone Eddy Fluxes to Maize', Boundary-Layer Meteorol. 15, 361-373.

Zeller, K., Massman, W. J., Stocker, D., Fox, D. G., Stedman, D. and Hazlett, D.: 1989, 'Initial Results from the Pawnee Eddy Correlation System for Dry Acid Deposition Research', USDA For. Serv. Res. Pap. RM-282, U.S. Dept. of Agric. For. Serv., Fort Collins, CO. 
